\title{
Cyclic adenosine monophosphate-responsive element-binding protein activation predicts an unfavorable prognosis in patients with hepatocellular carcinoma
}

\author{
This article was published in the following Dove Press journal: \\ OncoTargets and Therapy \\ 29 May 2014 \\ Number of times this article has been viewed
}

\author{
Lingxiang $\mathrm{Yu}^{*}$ \\ Xiaodong Guo* \\ Peirui Zhang \\ Ruizhao Qi \\ Zhiwei Li \\ Shaogeng Zhang \\ Department of Hepatobiliary Surgery, \\ 302 Military Hospital of China, \\ Beijing, People's Republic of China \\ *These authors contributed equally \\ to this work
}

\begin{abstract}
Aim: To investigate the clinical significance of cyclic adenosine monophosphate-responsive element-binding (CREB) and phosphorylated CREB (pCREB) expression in human hepatocellular carcinoma (HCC).
\end{abstract}

Materials and methods: Immunohistochemistry and Western blot analyses were performed to detect the expression and subcellular localizations of CREB and pCREB proteins in 130 pairs of HCC and adjacent nonneoplastic liver tissues.

Results: Both immunohistochemistry and Western blot analyses showed that the expression levels of CREB and pCREB proteins in HCC tissues were significantly higher than those in the adjacent nonneoplastic liver tissues (both $P<0.001$ ). In addition, the combined upregulation of CREB and pCREB proteins (CREB-high/pCREB-high) was significantly associated with serum $\alpha$-fetoprotein $(P=0.02)$, tumor stage $(P<0.001)$, and tumor grade $(P=0.01)$. Moreover, HCC patients with CREB-high/pCREB-high expression showed shortest 5-year disease-free survival and 5-year overall survival (both $P<0.001$ ). Furthermore, the multivariate survival analysis found that the combined upregulation of CREB and pCREB proteins may be an independent unfavorable prognostic factor for both 5-year disease-free survival and 5-year overall survival (both $P=0.01$ ) in HCC.

Conclusion: Our data indicate for the first time that the activation of the CREB protein may be associated with tumor progression in HCC, and may serve as a valuable marker of prognosis for patients with this malignancy.

Keywords: hepatocellular carcinoma, cyclic AMP-responsive element-binding protein, tumor progression, prognosis

\section{Introduction}

Hepatocellular carcinoma (HCC) represents the fifth-most frequent human malignancy in terms of its incidence rate and the third-leading cause of cancer-related deaths globally. ${ }^{1}$ More than 700,000 new cases are diagnosed worldwide, and more than 600,000 deaths attributed to HCC annually. ${ }^{2} \mathrm{HCC}$ is especially prevalent in certain areas of Asia and Africa. ${ }^{3}$ As a highly aggressive solid tumor, HCC is characterized by fast infiltrating growth, early metastasis, high-grade malignancy, and poor prognosis. ${ }^{4}$ Despite improvements in diagnostic and therapeutic approaches, the 5-year survival rate of this cancer is merely $7 \%$, because of a high incidence of postoperative metastasis and recurrence, and the high resistance of HCC to chemotherapy. ${ }^{5}$ This disappointing outcome clearly suggests that the current knowledge regarding diagnosis, prevention, 
and treatment of this cancer is insufficient. Therefore, further investigations should focus on the identification of specific biomarkers with high sensitivity and specificity for HCC in order to screen patients with poor prognosis or at high risk of early recurrence and to serve as a basis for understanding the complex molecular mechanisms governing the progression and aggressiveness of this malignancy.

The cyclic adenosine monophosphate (cAMP)-response element-binding (CREB) protein, which belongs to a subfamily of the leucine zipper with basic domain family, is a $43 \mathrm{kDa}$ basic/leucine-zipper transcription factor. ${ }^{6}$ It binds to the cAMP-responsive element (TGACGTCA) on the somatostatin promoter in the presence of cAMP, and activates transcription in response to a variety of extracellular signals, such as hormones, growth and neurotrophic factors, neurotransmitters, and membrane depolarization. ${ }^{7}$ CREB plays crucial roles in cell differentiation, proliferation, cell-cycle progression, survival, development, and glucose metabolism through being activated by cAMP, growth factors, hormones, retinoids, cytokines, and prostaglandins via multiple signaling pathways. ${ }^{8}$ Pathologically, the CREB protein has been demonstrated to be upregulated in several human malignancies and act as an important oncogene. ${ }^{9}$ In particular, a study by Abramovitch et al ${ }^{10}$ showed that CREB could promote the tumor progression of HCC by supporting angiogenesis and rendering HCC cells resistant to apoptosis. Kovach et al $^{11}$ also found that total CREB and phosphorylated CREB (pCREB) proteins were both significantly elevated in HCC versus normal liver. However, their clinical implications are still unclear. The aim of this study was to investigate the correlations of CREB and pCREB expression with clinicopathological characteristics and HCC patient survival.

\section{Materials and methods} Patients and tissue samples

This study was approved by the Research Ethics Committee of the 302 Military Hospital of China (PLA30200198). Written informed consent was obtained from all of the patients. All specimens were handled and made anonymous according to ethical and legal standards.

In this retrospective study, a total of 130 patients with primary $\mathrm{HCC}$ who underwent a curative liver resection at the 302 Military Hospital of China in Beijing were enrolled. A total of $130 \mathrm{HCC}$ and adjacent nonneoplastic liver tissues obtained from these patients were retrieved from the tissue bank of the Department of Pathology in the hospital. These patients had been diagnosed with HCC between 2001 and 2006. None of the patients recruited in this study had chemotherapy or radiotherapy before the surgery. HCC diagnosis was based on World Health Organization criteria. Tumor differentiation was defined according to the Edmondson grading system. Liver function was assessed using the Child-Pugh scoring system. Tumor staging was determined according to the sixth edition of the TNM Classification of Malignant Tumors of the International Union Against Cancer. ${ }^{12}$ The clinicopathological features of 130 patients are summarized in Table 1.

The median follow-up period of all 130 patients with HCC was 8.6 years. Postoperative surveillance included routine clinical and laboratory examinations every third month, computed tomography scans of the abdomen, and radiographs of the chest every third month. After 5 years, the examination interval was extended to 12 months.

\section{Immunohistochemistry analysis}

Immunohistochemistry was performed to detect the expression patterns and the subcellular localizations of CREB and pCREB

Table I Association of combined CREB and PCREB upregulation with clinicopathological features of I 30 hepatocellular carcinoma patients

\begin{tabular}{|c|c|c|c|}
\hline $\begin{array}{l}\text { Clinicopathological } \\
\text { features }\end{array}$ & Case & $\begin{array}{l}\text { CREB-high/ } \\
\text { pCREB-high (n, \%) }\end{array}$ & $P$ \\
\hline \multicolumn{4}{|l|}{ Age (years) } \\
\hline$\leq 50$ & 72 & $32(44.44)$ & \multirow[t]{2}{*}{-} \\
\hline$>50$ & 58 & $28(48.28)$ & \\
\hline \multicolumn{4}{|l|}{ Sex } \\
\hline Male & 96 & $44(45.83)$ & \multirow[t]{2}{*}{ - } \\
\hline Female & 34 & $16(47.06)$ & \\
\hline \multicolumn{4}{|l|}{ Serum AFP } \\
\hline Positive $(\geq 400 \mu \mathrm{g} / \mathrm{L})$ & 72 & $40(55.56)$ & \multirow[t]{2}{*}{$0.02 *$} \\
\hline Negative $(<400 \mu \mathrm{g} / \mathrm{L})$ & 58 & $20(34.48)$ & \\
\hline \multicolumn{4}{|l|}{ Tumor stage } \\
\hline $\mathrm{TI}$ & 23 & 0 & \multirow[t]{4}{*}{$<0.00 I^{* *}$} \\
\hline $\mathrm{T} 2$ & 40 & $10(25.00)$ & \\
\hline T3 & 52 & $35(67.31)$ & \\
\hline $\mathrm{T} 4$ & 15 & $15(100.00)$ & \\
\hline \multicolumn{4}{|l|}{ Tumor grade } \\
\hline GI & 31 & $8(25.8 \mathrm{I})$ & \multirow[t]{3}{*}{$0.01 *$} \\
\hline $\mathrm{G} 2$ & 76 & $34(44.74)$ & \\
\hline G3 & 23 & $18(78.26)$ & \\
\hline \multicolumn{4}{|l|}{ Growth pattern } \\
\hline Trabecular & 101 & $45(44.55)$ & \multirow[t]{2}{*}{-} \\
\hline Nontrabecular & 29 & $15(51.72)$ & \\
\hline \multicolumn{4}{|l|}{ Cirrhosis } \\
\hline Yes & 86 & $40(46.5 I)$ & \multirow[t]{2}{*}{-} \\
\hline No & 44 & $20(45.45)$ & \\
\hline \multicolumn{4}{|l|}{ Underlying liver disease } \\
\hline Alcoholic & 25 & $12(48.00)$ & \multirow[t]{4}{*}{-} \\
\hline Hepatitis B & 49 & $22(44.90)$ & \\
\hline Hepatitis C & 35 & $16(45.71)$ & \\
\hline Unknown & 21 & $10(47.62)$ & \\
\hline
\end{tabular}

Notes: $* P<0.05 ; * * P<0.001$. 
proteins in HCC and adjacent nonneoplastic liver tissues following the protocol of our previous studies. ${ }^{13-15}$ The primary antibodies were rabbit monoclonal anti-CREB (ab32515; Abcam, Cambridge, UK) and rabbit monoclonal anti-pCREB (phospho S133) (ab32096; Abcam). The secondary antibody for the detection of primary antibodies was anti-rabbit immunoglobulin G (sc-3739; Santa Cruz Biotechnology, Dallas, TX, USA). The specificities of anti-CREB and anti-pCREB antibodies (as shown in Figure 1) were validated by Western blot analysis using CREB Blocking Peptide (ab4963, $0.5 \mu \mathrm{g} / \mathrm{mL}$, incubation at room temperature for 30 minutes; Abcam) and Phospho-CREB (Ser133) Blocking Peptide (1090, $0.5 \mu \mathrm{g} / \mathrm{mL}$, incubation at room temperature for 30 minutes; Cell Signaling Technology, Danvers, MA, USA). The negative controls were processed in a similar manner with phosphate-buffered saline instead of primary antibody. The positive CREB and pCREB expressions confirmed by Western blotting were used as positive controls for immunostaining.

\section{Evaluation of immunostaining results}

Immunohistochemistry results were evaluated by two independent experienced pathologists who were blinded to the clinicopathological data and clinical outcomes of the patients. Their scores were compared, and any discrepant scores were reexamined by both pathologists to reach a consensus score. The number of positive-staining cells in ten representative microscopic fields was counted, and the percentage of positive cells was calculated. The percentage scoring of positive tumor cells was $0(0)$, $1(1 \%-10 \%), 2(11 \%-50 \%)$, and $3(>50 \%)$. The staining intensity was visually scored and stratified as 0 (negative), 1 (weak), 2 (moderate), and 3 (strong). A final score was obtained for each case by multiplying the percentage and

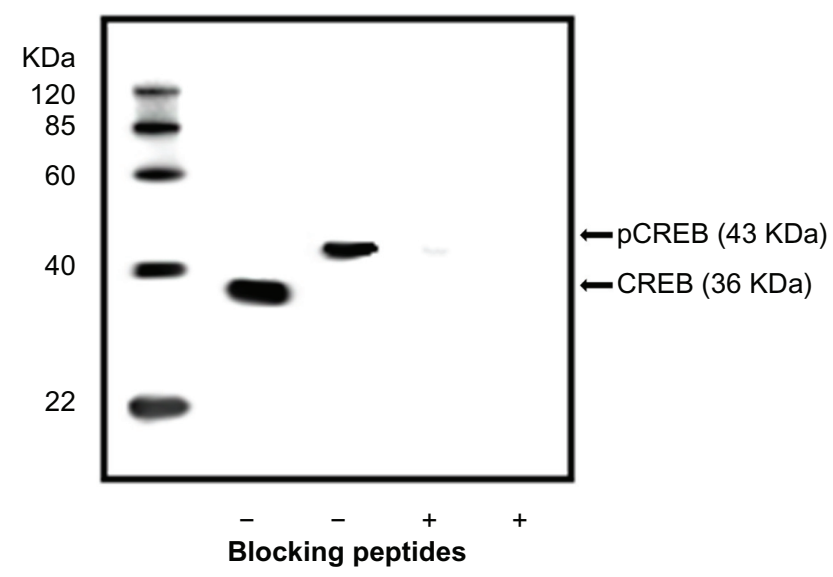

Figure I Specificities of anti-CREB and anti-pCREB antibodies. Western blot analysis of hepatocellular carcinoma tissues using CREB and PCREB antibodies with and without preincubation with respective blocking peptides. the intensity score. Therefore, tumors with a multiplied score less than the median of the total score for CREB ( median $=5.56)$ or pCREB (median $=4.48)$ were deemed to be low expressions of CREB or pCREB; all other scores were considered to be high expressions of CREB or pCREB.

\section{Western blot}

Western blot analysis was carried out according to the protocol of our previous studies. ${ }^{13,14}$ Rabbit monoclonal anti-CREB antibody (ab32515; Abcam) and rabbit monoclonal anti-pCREB (phospho S133) antibody (ab32096; Abcam) were used, and GAPDH antibody (CW0266, dilution 1:1,000; CoWin Biotech, Beijing, People's Republic of China) was used as the internal control. The relative CREB- and pCREBexpression levels were both indicated after normalization to GAPDH protein (internal control).

\section{Statistical analysis}

Statistical analysis was performed by SPSS version 13.0 for Windows (SPSS, Chicago, IL, USA) and SAS 9.1 (SAS Institute, Cary, NC, USA). The $\chi^{2}$ test was used to show differences in categorical variables. Correlations between CREB and pCREB expression were calculated using Spearman's correlation. Differences in patient survival were determined by the Kaplan-Meier method and log-rank test. A Cox regression analysis (proportional hazards model) was performed for the multivariate analyses of prognostic factors. Differences were considered statistically significant when $P<0.05$.

\section{Results \\ Expression patterns and subcellular localizations of CREB and PCREB proteins in HCC}

Expression patterns and subcellular localizations of CREB and pCREB proteins in 130 self-pairs of HCC and adjacent nonneoplastic liver tissues were observed by immunohistochemistry analysis. As shown in Figure 2, CREB and pCREB stainings were both primarily localized in the nucleus of both normal and tumor cells, and were higher in HCC tissues than those in adjacent nonneoplastic liver tissues. In addition, statistical analysis showed that the expression levels of CREB and pCREB proteins in HCC tissues were both significantly higher than those in the adjacent nonneoplastic liver tissues (both $P<0.001$, Figure 2C and F). Of note, the expression levels of CREB and pCREB in a high tumor grade $(\mathrm{G} 3 ; 6.62 \pm 1.78$ and $5.38 \pm 1.02$, respectively) were both significantly higher than in lower grades (G1-G2; $3.37 \pm 0.42$ and $2.91 \pm 0.33$, respectively; both $P=0.02$ ) HCC. Moreover, based on the scoring system 

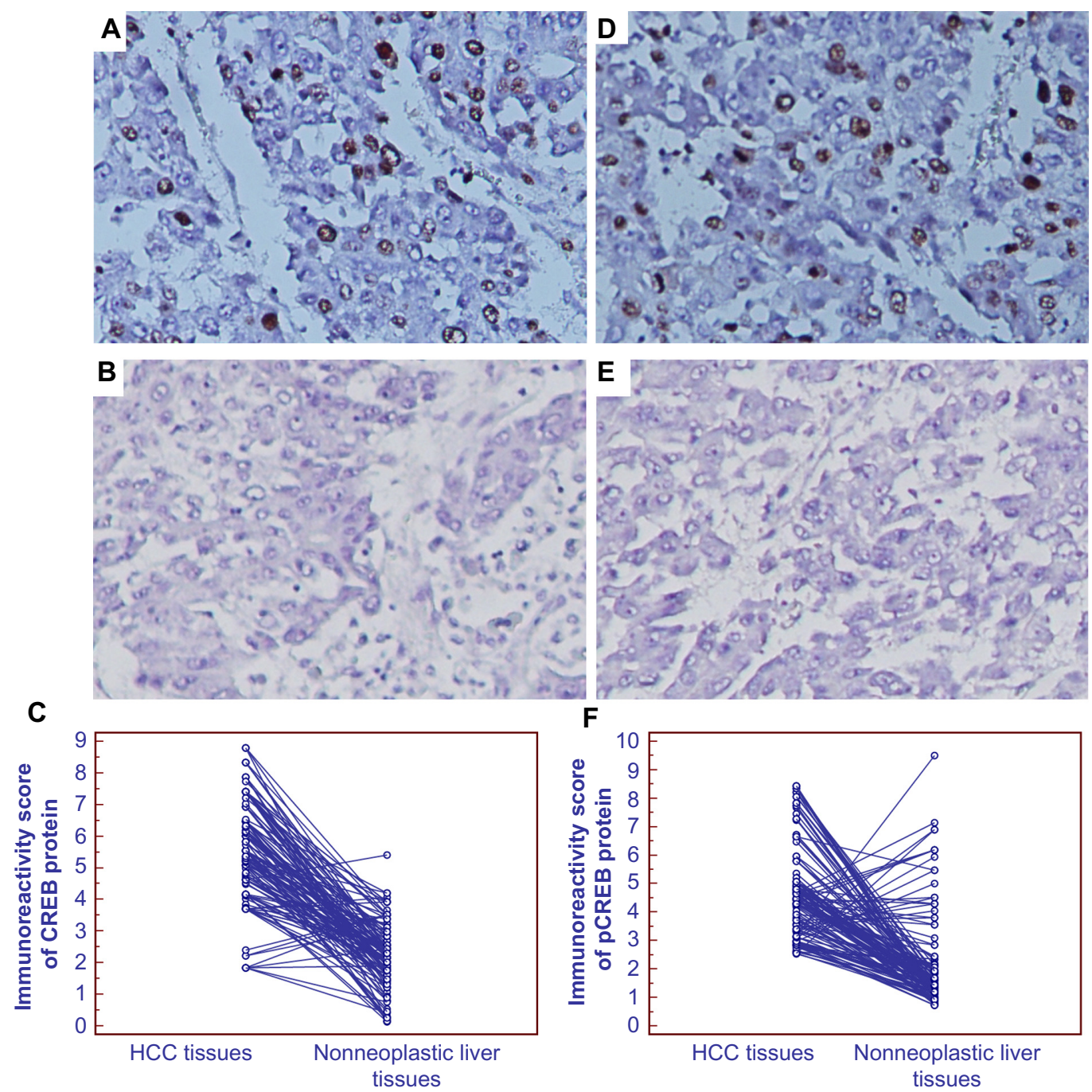

Figure 2 (A-F) Expression patterns and subcellular localizations of CREB and PCREB proteins in hepatocellular carcinoma (HCC) and adjacent nonneoplastic liver tissues. Representative immunohistochemistry images for CREB ( $\mathbf{A}$ and $\mathbf{B}$ ) and PCREB ( $\mathbf{D}$ and $\mathbf{E}$ ) proteins in HCC and adjacent nonneoplastic liver tissues, respectively (magnification $\times 200$ ). Statistical analysis showed that the expression levels of CREB and PCREB proteins in HCC tissues were both significantly higher than those in the adjacent nonneoplastic liver tissues (both $P<0.00$ I [C and $\mathbf{F}$ ], respectively).

used in the present study, 60 (43.08\%) cases showed high expression of both CREB and pCREB, $45(40.00 \%)$ cases showed low expression of both CREB and pCREB, 12 (9.23\%) cases were CREB-high and pCREB-low expression, and 13 (7.69\%) cases were CREB-low and pCREB-high expression. As determined by Spearman's correlation, CREB expression was closely correlated with $\mathrm{pCREB}$ expression $(r=0.68$, $P=0.002$, Figure 3). Of note, the results of the immunohistochemistry analysis were further confirmed with the findings of the Western blot analysis, as shown in Figure 4.

\section{Upregulation of CREB and PCREB proteins is associated with the aggressive clinicopathological features of HCC}

We then correlated immunoreactive scores of CREB and $\mathrm{pCREB}$ proteins with clinicopathological features of

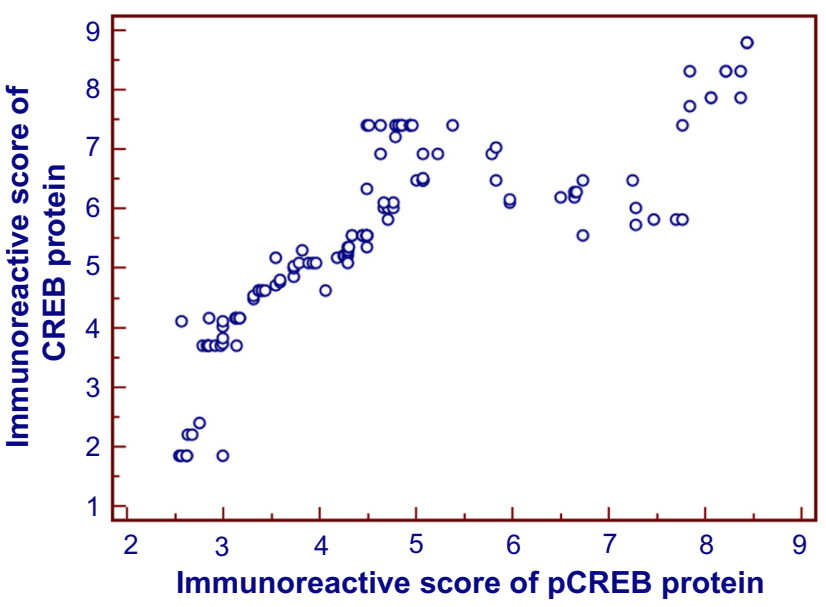

Figure 3 Scatter diagram of immunoreactive scores of CREB and PCREB proteins in hepatocellular carcinoma ( $\mathrm{HCC})$ tissues. As determined by Spearman's correlation, ${ }^{16}$ CREB expression was closely correlated with PCREB expression $(r=0.68, P=0.002)$. 

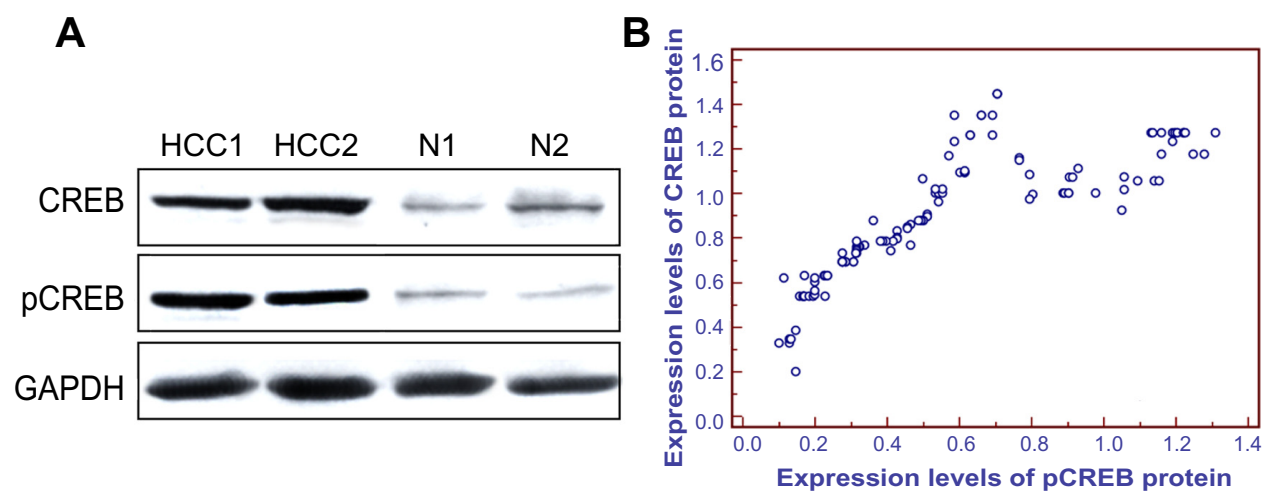

Figure 4 (A and B) Expression levels of CREB and PCREB proteins in hepatocellular carcinoma (HCC) and adjacent nonneoplastic liver tissues detected by Western blot. (A) Representative Western blotting of CREB and pCREB protein levels in HCC tissues and adjacent nonneoplastic liver tissues. (B) Scatter diagram of expression levels of CREB and PCREB proteins in HCC tissues detected by Western blot. Relative CREB- and pCREB-expression levels were both indicated after normalization to GAPDH protein (internal control). As determined by Spearman's correlation, ${ }^{16} \mathrm{CREB}$ expression was closely correlated with $\mathrm{PCREB}$ expression $(r=0.56, P=0.008)$.

HCC (Table 1). We found that the combined upregulation of CREB and pCREB proteins (CREB-high/pCREB-high) was significantly associated with serum $\alpha$-fetoprotein (AFP; $P=0.02$, Table 1$)$, tumor stage $(P<0.001$, Table 1$)$, and tumor grade $(P=0.01$, Table 1$)$.

\section{Upregulation of CREB and PCREB proteins predicts poor prognosis in HCC}

Five-year disease-free survival was observed in 30 (23.08\%) patients, whereas in 100 (76.92\%) patients, disease recurred, and $88(67.69 \%)$ died during the 5-year follow-up period. The association between coexpression of CREB/pCREB and the survival rates was tested by the Kaplan-Meier method. The $\chi^{2}$ value by log rank (Mantel-Cox) indicated a significant difference among different groups with regards to the conjoined expression status of CREB/pCREB (Figure 5A and B).
Results of pair-wise comparisons showed that statistically significant differences in disease-free survival and overall survival existed between CREB-high/pCREB-high patients and all of the other three groups (both $P<0.001$ ). In all four groups, CREB-high/pCREB-high patients had the poorest prognosis. More interestingly, disease-free survival and overall survival of patients with CREB-low/pCREB-high expression were both significantly shorter than those with CREB-high/pCREB-low (both $P=0.001$, Figure 5A and B), suggesting that high levels of the activated form pCREB may correlate with poor prognosis.

Furthermore, in a multivariate Cox model, including serum AFP, tumor stage, tumor grade, presence of cirrhosis, sex, age, and combined CREB/pCREB expression, we found that tumor stage $(P=0.009$ and 0.01 , Table 2$)$ and combined $\mathrm{CREB} / \mathrm{pCREB}$ expression (both $P=0.01$, Table 2) were
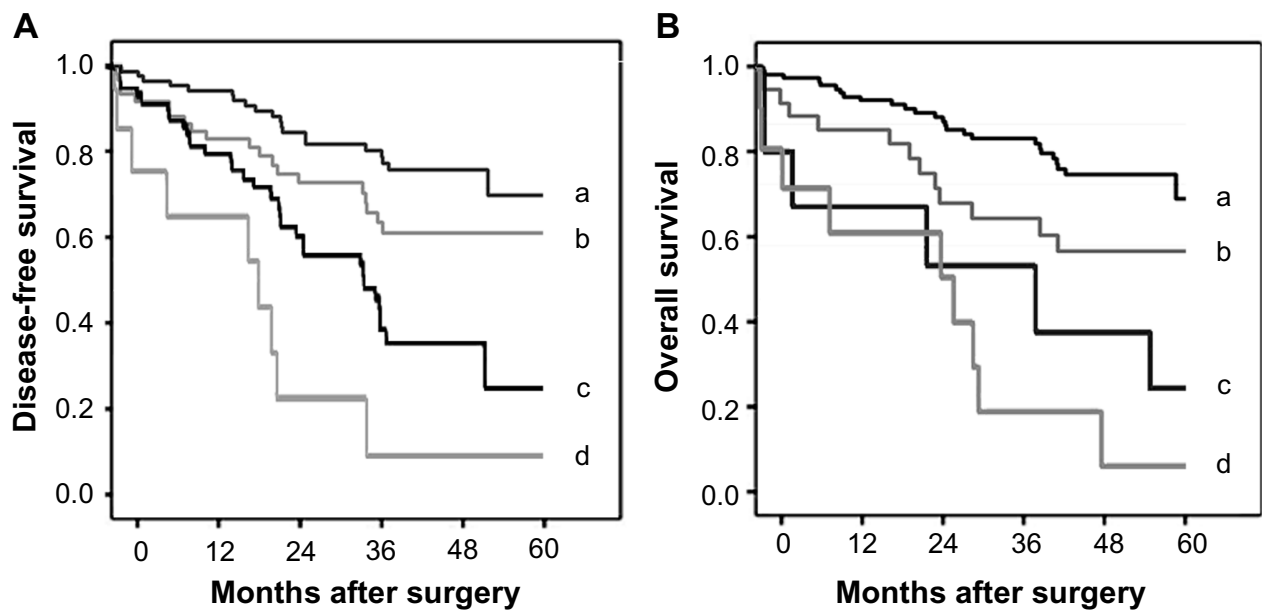

Figure 5 Disease-free survival and overall survival curves for four groups defined by the combined expression of CREB (A) and pCREB (B) in patients with hepatocellular carcinoma (HCC). CREB-low/pCREB-low (a); CREB-high/pCREB-low (b); CREB-low/pCREB-high (c); CREB-high/pCREB-high (d). Results by pair-wise comparisons showed that statistically significant differences of overall and disease-free survival existed between CREB-high/pCREB-high patients and all the other three groups (both $P<0.00 \mathrm{I}$ ). In all four groups, CREB-high/PCREB-high patients had the poorest prognosis. 
Table 2 Multivariate survival analysis of 5-year overall and disease-free survival in 130 patients with hepatocellular carcinoma

\begin{tabular}{|c|c|c|c|c|c|c|}
\hline \multirow[t]{2}{*}{ Features } & \multicolumn{3}{|c|}{ 5-year overall survival } & \multicolumn{3}{|c|}{ 5-year disease-free survival } \\
\hline & HR & $95 \% \mathrm{Cl}$ & $P$ & HR & $95 \% \mathrm{Cl}$ & $P$ \\
\hline Age & 1.132 & $0.316-3.516$ & - & 1.536 & $0.322-3.736$ & - \\
\hline Sex & 1.191 & $0.345-3.857$ & - & 1.559 & $0.357-3.831$ & - \\
\hline Serum AFP & 1.931 & $0.685-4.056$ & - & 1.953 & $0.615-4.273$ & - \\
\hline Tumor stage & 2.879 & $1.366-5.196$ & $0.009 * *$ & 2.686 & $1.386-6.009$ & $0.0 I^{*}$ \\
\hline Tumor grade & 1.563 & $0.609-4.088$ & - & I.55। & $0.607-4.466$ & - \\
\hline Presence of cirrhosis & 1.919 & $0.738-4.102$ & - & 1.921 & $0.793-4.219$ & - \\
\hline CREB/pCREB expression & 5.296 & $1.296-|1.66|$ & $0.01 *$ & 5.828 & $1.322-12.687$ & $0.01 *$ \\
\hline
\end{tabular}

Notes: $* P<0.05 ; * * P<0.01$.

Abbreviations: AFP, alpha-fetoprotein; $\mathrm{Cl}$, confidence interval; $\mathrm{HR}$, hazard ratio.

independent poor prognostic factors for both 5-year diseasefree survival and 5-year overall survival in HCC.

\section{Discussion}

As a common malignancy, HCC incidence is still on the rise in developing countries. It is generally believed that early detection offers curative treatment for HCC patients. Therefore, it is extremely important to develop effective screening strategies for high-risk patients. In the current study, we observed the expression patterns and subcellular localizations of CREB and pCREB proteins in $130 \mathrm{HCC}$ tissues and paired adjacent nonneoplastic liver tissues using immunohistochemistry and Western blot analyses. At first, we confirmed that the positive stainings of CREB and pCREB proteins mainly occurred in the nucleus of tumor cells in HCC tissues, and that the expression levels of the two proteins were significantly upregulated in HCC tissues compared with paired adjacent nonneoplastic tissues, suggesting the activation of the CREB protein in HCC. Since both the immunohistochemistry and Western blot results showed that CREB expression was closely correlated with pCREB expression, we further investigated the association of the combined expression of the two proteins with tumor progression of HCC. As a result, we found that the combined upregulation of CREB and $\mathrm{pCREB}$ proteins was significantly associated with aggressive clinicopathological features and poor prognosis in patients with $\mathrm{HCC}$, indicating for the first time that the coexpression of CREB and pCREB proteins may be a useful diagnostic and prognostic marker for HCC patients. These findings may be important for the prevention and treatment of this malignancy.

CREB functions as a regulator of the expression of several genes in response to hormones, ion fluxes, growth factors, and stress signals. ${ }^{17}$ CREB-binding sites (CRE1 and CRE2) are essential for cAMP-induced promoter II activity, which requires phosphorylation by cAMP-dependent protein kinase at serine 119 and 133 for interaction with deoxyribonucleic acid and ribonucleic acid polymerase II. ${ }^{18}$ Recent studies have identified several downstream genes of CREB, including the cell cycle-related genes cyclin A1, cyclin $\mathrm{B} 1$, and cyclin $\mathrm{D} 2$, the oncogene $\mathrm{Bcl}-2$, activated transcription factor 3, NF- $\mathrm{KB}$, signal-transduction proteins, and other growth-related genes. ${ }^{19,20}$ Accumulating evidence shows that CREB is overexpressed in several neoplastic cancers, functions as an important oncogene that promotes tumor cell growth, and is involved in the proliferation, survival, and metastasis of tumor cells. ${ }^{21-24}$ For example, CREB is present at a high level in human glioma tissues, ${ }^{21} \mathrm{CREB}$ is upregulated in malignant mesothelioma cells through an epidermal growth-factor receptor/protein-kinase A pathway, ${ }^{22}$ CREB is also found to be involved in the occurrence of breast cancer ${ }^{23}$ and CREB overexpression may counteract the suppression of growth in gastric cancer cells. ${ }^{24}$ Similarly to these previous studies, our data showed that CREB- and pCREB-expression levels were both significantly increased in HCC tissues versus nonneoplastic liver tissues. In addition, we observed that the combined upregulation of CREB and pCREB was significantly associated with advanced tumor stage, high tumor grade, high serum AFP levels, and unfavorable prognosis, suggesting that the activation of the CREB protein may serve as a molecular prognostic marker for HCC, and that CREB overexpression in combination with pCREB upregulation may be associated with even worse prognosis of HCC patients.

Taken together, these findings indicate for the first time that activation of the CREB protein may be associated with tumor progression in $\mathrm{HCC}$, and may serve as a valuable marker of prognosis for patients with this malignancy. Although the role of CREB in human tumor pathology has been explored extensively, its molecular mechanisms in different tumor types have not been fully elucidated. Further studies are needed to investigate the precise mechanisms of CREB in the progression of $\mathrm{HCC}$. 


\section{Disclosure}

The authors report no conflicts of interest in this work.

\section{References}

1. Jemal A, Bray F, Center MM, Ferlay J, Ward E, Forman D. Global cancer statistics. CA Cancer J Clin. 2011;61:69-90.

2. Kao JH, Chen DS. Changing disease burden of hepatocellular carcinoma in the Far East and Southeast Asia. Liver Int. 2005;25:696-703.

3. Kiyosawa K, Umemura T, Ichijo T, et al. Hepatocellular carcinoma: recent trends in Japan. Gastroenterology. 2004;127:S17-S26.

4. Nguyen VT, Law MG, Dore GJ. Hepatitis B-related hepatocellular carcinoma: epidemiological characteristics and disease burden. JViral Hepat. 2009; 16:453-463.

5. Dhanasekaran R, Limaye A, Cabrera R. Hepatocellular carcinoma: current trends in worldwide epidemiology, risk factors, diagnosis, and therapeutics. Hepat Med. 2012;4:19-37.

6. Shaywitz AJ, Greenberg ME. CREB: a stimulus-induced transcription factor activated by a diverse array of extracellular signals. Annu Rev Biochem. 1999;68:821-861.

7. Molnar P, Perrault R, Louis S, Zahradka P. The cyclic AMP response element-binding protein (CREB) mediates smooth muscle cell proliferation in response to angiotensin II. J Cell Commun Signal. 2014;8:29-37.

8. Alda M, Shao L, Wang JF, et al. Alterations in phosphorylated cAMP response element-binding protein (pCREB) signaling: an endophenotype of lithium-responsive bipolar disorder? Bipolar Disord. 2013;15:824-831.

9. Zhang X, Odom DT, Koo SH, et al. Genome-wide analysis of cAMPresponse element binding protein occupancy, phosphorylation, and target gene activation in human tissues. Proc Natl Acad Sci U S A. 2005;102:4459-4464.

10. Abramovitch R, Tavor E, Jacob-Hirsch J, et al. A pivotal role of cyclic AMP-responsive element binding protein in tumor progression. Cancer Res. 2004;64:1338-1346.

11. Kovach SJ, Price JA, Shaw CM, Theodorakis NG, McKillop IH. Role of cyclic-AMP responsive element binding (CREB) proteins in cell proliferation in a rat model of hepatocellular carcinoma. J Cell Physiol. 2006;206:411-419.

12. Kee KM, Wang JH, Lin CY, Wang CC, Cheng YF, Lu SN. Validation of the 7th edition TNM staging system for hepatocellular carcinoma: an analysis of 8,828 patients in a single medical center. Dig Dis Sci. 2013;58:2721-2728.
13. Guo X, Xiong L, Zou L, Zhao J. Upregulation of bone morphogenetic protein 4 is associated with poor prognosis in patients with hepatocellular carcinoma. Pathol Oncol Res. 2012;18:635-640.

14. Guo X, Xiong L, Sun T, et al. Expression features of SOX9 associate with tumor progression and poor prognosis of hepatocellular carcinoma. Diagn Pathol. 2012;7:44.

15. Guo X, Xiong L, Zou L, et al. L1 cell adhesion molecule overexpression in hepatocellular carcinoma associates with advanced tumor progression and poor patient survival. Diagn Pathol. 2012;7:96.

16. Kempi V. A FORTRAN program for ranking and for calculation of Spearman's correlation coefficient. Comput Methods Programs Biomed. 1985;21:123-125.

17. Sofi M, Young MJ, Papamakarios T, Simpson ER, Clyne CD. Role of CRE-binding protein (CREB) in aromatase expression in breast adipose. Breast Cancer Res Treat. 2003;79:399-407.

18. Johannessen M, Delghandi MP, Moens U. What turns CREB on? Cell Signal. 2004;16:1211-1227.

19. Luciani P, Buci L, Conforti B, et al. Expression of cAMP response element-binding protein and sodium iodide symporter in benign non-functioning and malignant thyroid tumours. Eur $J$ Endocrinol. 2003;148:579-586.

20. Coxon A, Rozenblum E, Park YS, et al. Mect1-Maml2 fusion oncogene linked to the aberrant activation of cyclic AMP/CREB regulated genes. Cancer Res. 2005;65:7137-7144.

21. Peng B, Hu S, Jun Q, et al. MicroRNA-200b targets CREB1 and suppresses cell growth in human malignant glioma. Mol Cell Biochem. 2013;379:51-58

22. Shukla A, Bosenberg MW, MacPherson MB, et al. Activated cAMP response element binding protein is overexpressed in human mesotheliomas and inhibits apoptosis. Am J Pathol. 2009;175: 2197-2206.

23. Zhang M, Xu JJ, Zhou RL, Zhang QY. cAMP responsive element binding protein-1 is a transcription factor of lysosomal-associated protein transmembrane- 4 beta in human breast cancer cells. PLoS One 2013;8:e57520.

24. Chen L, Yang Q, Kong WQ, et al. MicroRNA-181b targets cAMP responsive element binding protein 1 in gastric adenocarcinomas. IUBMB Life. 2012;64:628-635.
OncoTargets and Therapy

\section{Publish your work in this journal}

OncoTargets and Therapy is an international, peer-reviewed, open access journal focusing on the pathological basis of all cancers, potential targets for therapy and treatment protocols employed to improve the management of cancer patients. The journal also focuses on the impact of management programs and new therapeutic agents and protocols on

\section{Dovepress}

patient perspectives such as quality of life, adherence and satisfaction. The manuscript management system is completely online and includes a very quick and fair peer-review system, which is all easy to use. Visit http://www.dovepress.com/testimonials.php to read real quotes from published authors. 